\title{
Theory versus History of Social Economy ${ }^{1}$
}

Basically, any subject of human empirical cognition admits of a twofold approach: first, from the point of view of relationships between the components of reality in a given moment, or every moment, regardless of time and, second, from the point of view of the sequence and causality of the components of reality in time. This is why the same subject can be the focus of theoretical and nomothetical sciences, as well as idiographic, genetic and historical ones, depending on the terminology adopted. This duality of approach concerns the entire gamut of human cognition, despite appearances to the contrary. However, it has one aspect in the natural sciences and a different one in the moral sciences, as they were once called, which are now more often known as the humanities, of which a considerable portion could be classified as social sciences. The subject matter of physics, chemistry and biology is quite explicit, while the history of the development of the form of this same subject matter is the focus of geology, palaeontology and other similar sciences. However, the difference and variety of the scope and aspect of the studied phenomena are so considerable in this case that differentiating between these sciences does not pose any problems.

1 Translated from E. Taylor, Teoria a historia gospodarstwa społecznego, "Ruch Prawniczy, Ekonomiczny i Socjologiczny” 1962, 2, pp. 121-130 by Tomasz Żebrowski and proofread by Stephen Dersley and Ryszard Reisner. The translation and proofreading were financed by the Ministry of Science and Higher Education under 848/2/P-DUN/2018. 
It is a different story with the humanities, even more so with the social sciences, which are the primary concern here. Their subject matter as a rule admits of the dual approach mentioned earlier. Philology, grammar and stylistics have linguistics as their counterpart, which studies the history of language. Next to law studies, there is the history of law. It would seem that political and social histories have no theoretical counterparts. Meanwhile, sociology may be playing this role quite well, though it has perhaps not gone far enough in this direction yet. However, it has for a long time already been the case that economic history has accompanied the development of economics or political economy, whatever it is called, when understood as a theoretical science.

As far as economics is concerned, a certain confusion of ideas has been developing for a long time in this respect; deplorable misunderstandings and misconceptions have taken place, laden with far-reaching theoretical and practical consequences. This confusion of ideas takes two principal forms, concerning two issues that slightly differ from each other but are nonetheless closely tied and intertwined. These are, on the one hand, the distinction between the subjects of economics and economic history, and on the other, the viewing of economic development in terms of certain regularities.

Undeniably, the subject matter of the research of both economics and economic history is phenomena of exactly the same kind and scope. These are economic phenomena, that is, ones concerning social income, specifically the production, exchange and distribution of goods and services which making up social income. The only cause of contention in this regard is the scope of services included in it. Prima facie, unless one ponders the matter seriously, the simplest and - at the same time, to put it bluntly - the crudest way of drawing the distinction springs to mind. This involves distinguishing the areas of research pursued in the two fields in question by applying the criterion of a point in time to their common researchable phenomena. Thus, what has passed is assigned to economic history, while what is now and continues to be, belongs to the theory of economics. 
The distinction is indeed a mechanical one, but it is very convenient and expedient as a convention. It was commonly used in our country when Polish economic history was emerging and taking its first independent steps. Among our scholars in this field, a versatile, ingenious and subtle polymath, Franciszek Bujak, did not overly stress this approach but another profound and conscientious mind, Jan Rutkowski, was quite fond of it. After the First World War, he held that economic phenomena from before the war belonged to economic history, while after the Second World War, he assigned the phenomena that occurred prior to the war to this history. Naturally, he was not absolutely strict about the distinction, allowing for exceptions and making the distinction dependent on a number of conditions.

However, I have the impression that the successors of these great masters and many other Polish economic historians have changed this distinction-rather conventional in nature-into a dogma. They tend to think that if economists make past facts the subject of their study, they thereby encroach on their turf-like a poacher who does not belong there. They believe that if research is concerned with 19th-century facts, or even, say, the interwar period in Poland, ipso facto it belongs to economic history and thus it must be studied, necessarily and exclusively, by an economic historian and only the latter may supervise a doctoral dissertation in this field.

It seems that this stance is absolutely wrong and smacks of a division of labour between craftsmen or qualified workers implemented through agreements and work rules, and regulations or administrative provisions concerning particular occupations. Can research work be subject to such simplified and conventional divisions?

What does the work of economists and economic historians consist in? Economic theorists study economic phenomena in terms of such characteristics that are common to them and are prone to generalisations. For this purpose, they disregard the accidental or individual characteristics of particular phenomena and isolate them from the impact of 
their various configurations. They look for that which is more or less common, study various forms of relationships between phenomena and the conditions under which they occur, and try to establish the degree and kind of their universality, depending on various conditions. Meanwhile, the field of interest of economic historians covers something completely different. Their research focuses above all on establishing facts, wherever they are not absolutely certain, followed by finding any causality between them in the unique form of their unique sequence. In this way, they obtain a presentation and investigation of a sequence of facts over time in their entire diversity and completeness.

Obviously, these two types of research are interdependent and overlap. An economic historian in presenting and explaining a sequence of facts must make use of the concepts and causalities or interdependences developed by an economic theorist and, on the other hand, an economist must use the facts and interdependences established by an economic historian. On many an occasion, in certain areas, one type of work can be hardly distinguished from the other. In particular where the establishment of facts does not pose any difficulty, as for instance, where new or recent times are involved, economists, to achieve their research goals, must establish facts and their unique course and sequence. However, in such a case they encroach on the field of historical studies and more or less competently take on the role of historians. Likewise, economic historians may sometimes be forced to create a new research tool for themselves in the form of a concept or a kind of interdependence if they are not satisfied by those provided by theory. However, such a tool, naturally, will be rather temporary, as it will be closely adjusted to the subject matter at hand and thus may not be general or universal enough.

However, despite these mutual encroachments on their respective research turf, it is clear that the difference between the fields of learning under discussion does not lie in the time in which the studied facts arose, or the subject of research, but rather in the research method and goal. One research method is used for theory, and another one for his- 
tory. Theoretical study and historical study pursue different goals This is where the borderline between research by economic theorists and economic historians runs.

It is obvious that the generalisations arrived at by an economist stem not only from the present experiences but also past ones, from the accumulated knowledge and facts often supplied by economic historians. After all, for instance, although the beginnings of the quantity theory of money reach back to certain findings from the 16th and 17th centuries concerning contemporary events, its development is an outcome of long research into a more distant or more recent past. The research was verified by the study of the quite recent past, such as David Ricardo's work on inflation during the Napoleonic Wars and afterwards. After all, his High Price of Bullion ${ }^{2}$ cannot possibly be classed as historical scholarship. Nobody will include Thomas Tooke's famous study of the longterm movement of prices and money supply entitled History of Prices in economic history either. The study was not only crucial for the theory of money and credit, but also of considerable significance for economic history. Neither will anybody include the great work Purchasing Power of Money by Irving Fisher ${ }^{3}$ in economic history, despite the fact that it relies on a meticulous long-term analysis of prices and money supply. The same is true for a more recent work, namely the two-volume excellent work Theory of Prices by A.W. Marget ${ }^{4}$, already published in part prior to WWII.

To pass to another area of research, the entire theory of business cycles, or boom-and-bust if you wish, was born and developed-beginning with Clémant Juglar to W.C. Mitchell and contemporary theorists-by tracing the fluctuations of production, price, money and credit curves for the whole period from the early 19th century. Does the fa-

2 D. Ricardo, The High Price of Bullion: A Proof of the Depreciation of Bank Notes, London 1810.

3 I. Fisher Purchasing Power of Money. Its Determination and Relation to Credit, Interest and Crises, New York 1920.

4 A.W. Marget, The Theory of Prices, New York 1938. 
mous work Business Cycles by W.C. Mitchell ${ }^{5}$ belong to economic history because it studies not only the present but above all the past? Don't theorists have a right to rely on historical induction carried out by others or themselves? Can't they verify their theoretical claims using data from the past?

This author believes that such a stance would be clearly absurd. What matters most is how, using what method, for what purpose and from what point of view a given group of facts is considered, regardless of whether they belong to the past or the present. Besides, how very artificial and frail this distinction is, between the present and the past. In spite of all upheavals, reality is continuous and the past imperceptibly turns into the present: our roots are always in the past, while the present gives sense to the past.

There is no doubt that economics may base its generalisations on the study of the systematised facts which pertain to the present. To this end, it uses the descriptive method as a tool. It resembles the historical method and its results form a branch of economics sometimes referred to as descriptive economics. However, it may also be well-supported by facts from the past, and the further back it reaches, the more it needs the material supplied and digested by economic history. Moreover, it must always be careful to be competent enough in cases where it establishes facts and connections between them by itself, out of necessity, because economic history has not processed a given portion of material yet.

Now, we arrive at the most significant aspect of the dispute. No economist in their right mind would take facts from distant past, to use them as grounds for theoretical generalisations, from somewhere else than the works of economic historians or historians as such. The matter becomes awkward only in relation to recent times, the memories of which persist in the current generation and supply material for study from one's own observations and experiences or easily accessible sources of information. In this time range, the historian and theorist meet. It even looks as

5 A.F. Burns, W.C. Mitchell, Measuring Business Cycles, New York 1946. 
if they have competed with each other since they describe and present the same material. A historian does this to record the course of events, while a theorist has to reconstruct these events and their course when the historian has not processed them or has not accounted for this aspect of phenomena that the theorist is interested in. However, a different goal is pursued by a historian and a different one by a theorist. They use different methods. The fact that they both study the same scope of facts is not only recommended and desirable but also proper.

An example will elucidate the matter for us. A great deal of interest is aroused by economic phenomena related to covering the costs of the reconstruction of the country and government expenses largely through the issuance of paper money in Poland in the period of inflation in 19191927. An economic historian has a lot to work on to trace the course of economic phenomena, present attempts at a reform, their successes and failures, and policies pursued, etc. However, the same issues, after they are determined and causal connections between them are established, are of great significance for theorists. They may also determine these issues, if they have not been determined accurately enough yet, or guide them in the direction of questions they wish to investigate. One of such questions could be inflation, that is, the relationship between changes in the amount of money and the availability of credit, on the one hand, and the rates of exchange, prices, interest, entrepreneur's profit, wages, manufacturing and national income on the other. It is quite clear that historians will not do this work without appropriate education and talent. If they have them, some conclusions might be ventured, but then such historians would be acting as theorists. This kind of work calls for a theorist, but a theorist will welcome the work of a historian, supplying and interpreting facts concerning a given period. Theorists will gladly avail themselves of them but if they are not available, they must do the descriptive work on their own and tie it to theoretical investigations. The presentation and preliminary processing of material will not pose any major difficulties, owing to the availability and abundance of 
sources. Thus, both a historian and a theorist may work in this area, but each pursuing a different goal and employing a different method.

Let us turn to another issue, very close to the previous one in both time and nature, namely, the course the Great Depression took in interwar Poland in 1929-1933 or even 1929-1937. What a rich and multifaceted area of research it is for a historian. However, yet more interesting, or even exciting questions arise here for an economic theorist. The analysis of the adopted economic policies - especially monetary, credit and fiscal policies - and their effectiveness, helps decide if the so-called classic policy of credit crunch and constant value of money is effective, and under what conditions, for overcoming a crisis. Alternatively, if the policy of liberal credit and directed money, aimed at full employment, is more or less effective, and if so under what conditions

An analogous problem springs to mind as a subject of investigation of paramount importance for a theorist in even more recent times, namely, the "economic miracle" in West Germany in the years following the Second World War. Do theorists have to refrain from theoretical investigations only because no historian has studied this problem? Even if a historian has studied it, in all likelihood their work will not supply a theorist with the specific information they are most interested in, because of the special question they are working on. A historian is not aware of the significance of certain pieces of information for the issue at stake. Is a theorist then to stop encroaching on the descriptive and historical study of the relevant material in such a situation? Such a stance would be narrow-minded and pedantic.

Let us stress yet once again: it is not the time range, but rather the goal and method of research that separate the research subjects of economics and economic history. It appears that the simplifications and ideas of economic historians which are inconsistent with this view, are, to some degree, a belated response to, and a relic of, a certain longpassed period in the development of economics. In it, the criticism of the principle of economy, being a foundation of generalisations in economic 
theory, since it was conceived of as a motive of action, led the older German historical school to the assertion that economic laws were of a historical nature. Next, the conclusion was finally drawn that there were no theoretical economic laws whatsoever, economic theory could not exist and it should be replaced by economic history and the laws of development it formulated.

As a result, the teaching of economics morphed into the teaching of economic history and the ways of developing social economy, while chairs of economics were taken over by economic historians. Thus, Gustav F. von Schmoller, the representative of an already not so radical younger realistic historical school, excited by a dispute with Carl Menger, said loudly that at German universities, at the chairs of social economy, there was no place for abstract theorists and that positions were only available for realistic historians ${ }^{6}$ (Untersuchungen über die Methode der Sozialwissenschaften, 1883). The rule was also extended to the history of economic thought, although by its very nature it can only be practiced successfully by an expert theorist. However, since theory was to be replaced by history, in this field, too, a theorist was to be replaced by a historian. The outcomes of this attitude were deplorable, as were the ensuing appointments to professorships. Germany paid very dearly for them. Economics soon went into decline there, almost collapsed and stopped being respected abroad. Only slowly and gradually, against great obstacles, did it recover in the 20th century. As far as practice is concerned, the catastrophic inflation in Germany after the First World War resulted to a large extent from the so-called state theory developed by G.F. Knapp, which prevailed in Germany as regards money. It was a product of the anti-theoretical Historical School of economics.

The conclusions drawn by the Historical School, in particular the older one, from the proposition on the historic nature of economic laws were completely wrong. They followed from the ambiguity of the prop-

6 C. Menger, Untersuchungen über die Methode der Sozialwissenschaften, Leipzig 1883. 
osition in question. The proposition itself, properly understood and interpreted, is absolutely right and real.

It is undeniably right to say that economic laws are historically determined. Depending on the generality and universality of their assumptions, they concern some shorter or longer development periods while those that use the most general assumptions are valid in respect of several development periods or even may concern any aspect of social economy in general, admitting of some general common assumptions. The younger historical school found, because of the evolution of its views, that there existed similar, so-called "periodic" economic laws. Marxism, too, after initial misunderstandings, believes now in a similar historic nature of economic laws. It admits not only single-period, but also multi-period or "common” economic laws, as they are called by Oskar Lange. ${ }^{7}$ The latter extend to "all social formations whose economic base has ... common characteristics", which often makes their operation very regular. These single- or multi-period laws are theoretic and nomothetic in character. They ought to be distinguished from another understanding of the historic nature of economic laws, namely, as laws of development or laws of economic development. At this juncture, we arrive at the second question, relating to the proper distinction between the scopes of research of economics and economic history.

In essence, development laws cannot substitute for theoretical economic laws, nor may they replace them. They concern different things. The questions they are expected to answer are simply different. Their goal is to provide causal explanations of how the quantities of the economic system changed over time, accounting for their interdependence and relationships. Since what is meant here is how past phenomena changed over time, a historical approach naturally comes to mind, prima facie so to speak. Thus, economic historians usually believe that it is their task to make such a synthesis and discover laws of development. Many such syntheses have been made, relying on the study of the most

7 O. Lange, Ekonomia polityczna I, Warszawa 1959, p. 65. 
important characteristics of the past and their mutual ties, and projecting the experience gathered hitherto onto the future. Though frequently very interesting and suggestive, they are as a rule are one-sided, since they suffer from a fundamental, unavoidable and inevitable defect arising from the very heart of the matter, namely the incompleteness of induction and latitude in generalisations. As a result, they easily move onto the field of philosophy of history.

However, contrary to the practice and opinions of economic historians, it is also possible to approach economic development theoretically. Not everything that has happened and occurs in time must necessarily be approached from a historical point of view. As regards the generalisations of causalities and interdependences, rather than their individual occurrence, the field is wide open for theoretical studies. Economists of the past tried to consider economic development by building its model on the basis of certain assumptions and assertions regarding the changes of and relationships between particular economic factors. Such attempts sometimes also offer a vision of the end of development. Adam Smith revealed the principal reason of changes in an economic system, namely accumulation and investment, and also another collaborative one, namely technological progress related to the division of labour. With the classical economists, who introduced the third factor of population growth, in particular David Ricardo, a clear theory of development had emerged, which was later used by Karl Marx, who advanced a consistent, comprehensive and independent theory of development. Assuming the classical construction of a diverse, not necessarily explicit connection between the changes of economic factors, John Stuart Mill suggested the possible existence of a few variously combined models of economic development.

Ultimately, all these theories encompass more than just economic phenomena, the ties between them and interdependences. They go beyond these, advancing propositions on the changes of economic factors. In some, this is conscious and deliberate, as is the case with Marxism, 
which wants to give-and gives - more than a mere theory of economic life. Where this is unconscious and unintentional, an unsatisfactory distinction between historical problems, possibly even philosophical and sociological ones, and theoretic-economic ones, is to blame.

At present, there is a tendency in economics to approach from a different angle the question of changes in the quantities of an economic system. This reflects the need to make a cognitive distinction between the changes of quantities, or economic system elements, following from their interaction in movement and the changes thereof following from changes in economic factors. In that case, the analysis of one's own changes of economic factors is not necessary anymore. Research in such a limited scope is referred to with the new name of theory of growth, to distinguish it from the broader concept of economic development. The latter also encompasses economic factors being practically and in principle independent variables of an economic system. If they are brought into the equation, it becomes complicated and less comprehensible.

This stance is right and justified. The theory of economics does not have to limit itself to statics only, to the study of how dependent variables, or system elements, adjust to the movement of external independent variables that upset the balance of the former. It may and should build economic dynamics and it is the theory of growth that attempts to make economic research more dynamic in response to widespread calls. It should provide a theory of the process of changes of interrelated quantities, or economic elements, as they interact as a result of and during movement. These elements include the quantities, their growths and losses, of capital, production, consumption, investment and accumulation. Furthermore, it must be able to explain not only the mechanism of movement, but also its forms, such as cyclicity, and find out whether their causes are endogenous or possibly exogenous.

The theory of growth understood in this way has two different trends, employing two different methods. One determines simply the direction 
and ways social economy has hitherto changed in time, and various configurations of the underlying causes. Actually, this is still a historic approach that only slightly deepens the traditional theory of development. It does not provide any insight into the mechanism of changes. This is the character of the syntheses by some economists such as W.A, Lewis, W.W. Rostow and others. The other trend closely reflects the methodological assumptions of the theory of growth. It has already produced interesting results, in the work of Michał Kalecki, R.S. Harrod, E.D. Domar and others, showing that the influence of historicism has already been shaken off. Consequently, it provides a deeper independent insight into economic phenomena and after its results are combined with the results of other studies, it is capable of providing effective guidelines for managing and planning economic life.

As can be seen from the above brief review, the introduction of the conception of alleged development laws by historicism paradoxically led in fact to the opposite effect, i.e. to the rise of a nomothetic theory of growth. This was only possible thanks to the precise and proper separation of the subjects of research of economic theory and history. The misunderstanding as to the subject of research pursued by these two branches of learning and separating them using the criterion of the time at which the studied phenomena occurred and not that of the goal and method of study, has proven to be disastrous - always and everywhere. The research in these branches must be based on correct methodological assumptions. Then, they do not get in each other's way and harmoniously collaborate for the benefit of human knowledge.

\section{Literature}

Burns A.F., Mitchell W.C., Measuring Business Cycles, New York 1946. Fisher I., Purchasing Power of Money. Its Determination and Relation to Credit, Interest and Crises, New York 1920. Lange O., Ekonomia polityczna I, Warszawa 1959. 
490 | Edward Taylor

Marget A.W., The Theory of Prices, New York 1938.

Menger C., Untersuchungen über die Methode der Sozialwissenschaften, Leipzig 1883.

Ricardo D., The High Price of Bullion: A Proof of the Depreciation of Bank Notes, London 1810. 

